\title{
Effect of high energy X-ray irradiation on the nano-mechanical properties of human enamel and dentine
}

\section{Xue LIANG(a) \\ Jing Yang ZHANG (a) \\ lek Ka CHENG(a) \\ Ji Yao LI(b)}

(a) State Key Laboratory of Oral Diseases, Sichuan University, Chengdu, China

(b)West China School of Stomatology, Sichuan University, Chengdu, China

Declaration of Interests: The authors certify that they have no commercial or associative interest that represents a conflict of interest in connection with the manuscript.

Corresponding Author:

Ji Yao Li

E-mail: jiyao_li@aliyun.com

DOI: 10.1590/1807-3107BOR-2016.vol30.0009

Submitted: Mar 09, 2015

Accepted for publication: Jun 19, 2015

Last revision: Sep 03, 2015

\begin{abstract}
Radiotherapy for malignancies in the head and neck can cause common complications that can result in tooth damage that are also known as radiation caries. The aim of this study was to examine damage to the surface topography and calculate changes in friction behavior and the nano-mechanical properties (elastic modulus, nanohardness and friction coefficient) of enamel and dentine from extracted human third molars caused by exposure to radiation. Enamel and dentine samples from 50 human third molars were randomly assigned to four test groups or a control group. The test groups were exposed to high energy X-rays at 2 Gy/day, 5 days/week for 5 days (10 Gy group), 15 days (30 Gy group), 25 days (50 Gy group), 35 days (70 Gy group); the control group was not exposed. The nanohardness, elastic modulus, and friction coefficient were analyzed using a Hysitron Triboindenter. The nano-mechanical properties of both enamel and dentine showed significant dose-response relationships. The nanohardness and elastic modulus were most variable between 30-50 Gy, while the friction coefficient was most variable between 0-10 Gy for dentine and 30-50 Gy for enamel. After exposure to X-rays, the fracture resistance of the teeth clearly decreased (rapidly increasing friction coefficient with increasing doses under the same load), and they were more fragile. These nano-mechanical changes in dental hard tissue may increase the susceptibility to caries. Radiotherapy caused nano-mechanical changes in dentine and enamel that were dose related. The key doses were $30-50$ Gy and the key time points occurred during the $15^{\text {th }}-25^{\text {th }}$ days of treatment, which is when application of measures to prevent radiation caries should be considered.
\end{abstract}

Keywords: Radiotherapy, High-Energy; Dental Caries; Mechanical Phenomena; Dental Enamel; Dentin.

\section{Introduction}

Patients with malignant tumors in the head and neck region are often treated with radiation. ${ }^{1}$ This treatment can be effective. However, because of the typical normal tissue reactions that occur after irradiation, radiation treatment is often accompanied by complex oral complications affecting the salivary glands, ${ }^{2}$ oral mucosa, ${ }^{3}$ bone, masticatory musculature and dentition. ${ }^{4,5}$ Irradiation of the enamel and dentine of the teeth can influence their nano-mechanical structure by decreasing their ultimate tensile 
strength $\mathrm{th}^{6,7}$ and fracture resistance; this is also true of restored teeth ${ }^{8}$. Irradiation also adversely affects the bonding of resin-based composites to enamel and dentine, causing damage to restored teeth. ${ }^{9}$ This process often results in severe damage to the teeth, called radiation caries.

Radiation caries is a rapidly developing and highly destructive form of tooth decay, leading to the amputation of crowns and complete loss of dentition..$^{10}$ The risk of rampant tooth decay, with its sudden onset, is a lifelong threat. In dental research, radiation exposure to the major salivary glands causes a change in the composition of saliva qualitatively as well as a permanent quantitative reduction in secretion; this process contributes to the carious process. ${ }^{11}$ Indeed, radiation-induced hyposalivation is considered to be the most important etiological factor for dental caries. $^{2,12,13}$ However, in recent years, some scientists have suggested that direct radiation damage can ratchet up the progression of radiation caries; in their studies, morphological and physical changes in both human and bovine dentine were documented after radiotherapy. ${ }^{14,15,16,17}$ Unfortunately, the explanation regarding changes in the nano-mechanical properties of teeth has generated controversy in dental literature, and no in vivo study has reported the crucial radiotherapy dose-time relationship regarding the prevention of radiation caries. In vitro studies have limitations with regard to clinical conclusions. Findings from these studies have generated controversy because of the potential influence of the storage medium ${ }^{18,19}$ and the accuracy of the different methods and devices used; chemical reactions, ionizing radiation, and the mechanical test procedure may affect the surface of the enamel and dentine. Thus, effective evaluation of the effects of high energy $X$-ray radiotherapy on enamel and dentine needs to be performed in a systematic and thorough way. This can be done in part by measurement of the friction coefficient. Clinically, radiation damage to the surface of teeth leads to increased friability and breakdown (accompanied by wear of the incisal and occlusal surfaces), and complete amputation of the crown can occur. The main damage on the surface is brittle delamination, which may yield insufficient wear behaviors. In order to study the wear behavior of radiation-treated teeth, friction experiments can evaluate 'fretting wear' or in dental tribology terms, 'abrasive wear'.

In the present study, the effects of high energy $\mathrm{X}$-ray irradiation on the nano-mechanical properties (elastic modulus, nanohardness and friction coefficient) of enamel and dentine were investigated. We tested the hypothesis that high energy X-ray irradiation at different doses adversely affects the nano-mechanical properties of dental hard tissue.

\section{Methodology}

\section{Preparation of specimens}

Freshly extracted human third molars were collected with informed donor consent and were used for all experiments at the clinic of Oral and Maxillofacial Surgery of the West China Hospital of Stomatology from January 2012 to December 2012. The donors were aged 18-25 years old and were healthy with no age related diseases such as osteoporosis or systematic diseases. The teeth were removed one year after complete eruption. Caries free maxillary third molars were extracted and observed with a stereo microscope (X10; Olympus Optical Co. Ltd., Tokyo, Japan); molars with intact enamel and no white spots, cracks, or enamel hypoplasia were chosen and stored at $4^{\circ} \mathrm{C}$ in $0.2 \%$ thymol (Sinopharm Chemical Reagent Co. Ltd., Shanghai, China) for further examination. The teeth were obtained under a protocol (2011017) that had been analyzed and approved by the Ethical Committee of the West China Hospital of Stomatology, Sichuan University, Chengdu, China. The teeth were stored in physiological sodium chloride solution $(0.9 \% \mathrm{NaCl}$, Kelun Co. Ltd., Chengdu, China) that was renewed daily at $4^{\circ} \mathrm{C}$, and samples were stored for $<3$ months before experimentation. The suitability of the physiological sodium chloride solution as a storage medium for the dentine samples has been demonstrated in previous studies. ${ }^{20,21}$ Fifty molars with intact enamel and no white spots, cracks, or enamel hypoplasia were chosen for investigation in this study from 569 extracted molars. The residual tartar, alveolar bone, and soft tissue were removed before use, and then the molars were washed repeatedly with clean water. A water cooled diamond saw (Struers Minitom, Struers Ltd., Copenhagen, Denmark) was used to cut the molar into two pieces 
from the cemento-enamel junction with low speed; the dental pulp was extracted from the cross section of the tooth root. Then the molar was washed with deionized water and stored in deionized water for 24 hours. Occlusal sections were obtained from crowns and roots using a diamond coated band saw (Exakt Trennschleif system; PSI GruÈ newald, Laudenbach, Germany) under running water. Rectangular slabs (approximately $3 \times 4 \times 1.5 \mathrm{~mm}^{3}$ ) were prepared (Exakt Trennschleif-system) and were subsequently embedded in a chemical-polymerizing resin (Technovit 4071: Kulzer, Wehrheim, Germany). Finally, they were polished using successively decreasing grain sizes (1000, 2000, 3000 and 4000; Struers, Copenhagen, Denmark) until the residual thickness of the epoxy resin blocks was approximately $5 \mathrm{~mm}$.

\section{Irradiation procedure}

The 50 molar samples were randomly allocated into groups of 10 teeth per group using a random number table for assignment to the 10 Gy group, the 30 Gy group, the 50 Gy group, the 70 Gy group and the control group. The four test groups of samples were irradiated using an Elekta VMAT (Elekta AB, Stockholm, Sweden) with the following characteristics: monitor units (MUs), 100; file size (FSZ), $10 \mathrm{~cm} \times 10 \mathrm{~cm}$; source-surface-distance, $100 \mathrm{~cm}$; and field size, $20 \mathrm{~cm} \times 20 \mathrm{~cm}$. Irradiation was carried out daily (2 Gy/day, 5 days/week) for 5 days (10 Gy group), 15 days (30 Gy group), 25 days (50 Gy group) and 35 days (70 Gy group). The maximum dose delivered was $70 \mathrm{~Gy}$, which was similar to the total dose used clinically for the treatment of head and neck cancer. All irradiations of specimens were carried out in an manner analogous to clinical treatment (Figure 1) in physiological saline solution. ${ }^{22} \mathrm{~A}$ fifth group of samples (the control group) was not treated with radiation to ensure that the storage time and solution had not weakened the samples. In each group, ten enamel and ten dentine specimens were examined.

\section{Triboindente testing}

Triboindente testing was performed at the Tribology Research Institute, Key Laboratory for Advanced Technology of Materials of Ministry of Education, Southwest Jiaotong University, Chengdu
Sichuan by a senior researcher who was blinded to the sample groupings. For each group, the testing was performed on the day of the final radiation dose; the control group was tested on the same day as the 70 Gy group. A Triboindenter (TI750: Hysitron, Minneapolis, USA) with a Berkovich diamond indenter was used for measuring the nano-mechanical parameters regarding load control testing under constant ambient conditions $\left(24^{\circ} \mathrm{C} ; 35 \% \mathrm{H}\right)$. Figure 2 shows the indentation areas. The indenter was loaded up to a maximum of $8 \mathrm{mN}$, followed by a constant load hold period of $30 \mathrm{sec}$ at the maximum load, and unloaded with a constant loading rate of $40.0 \mathrm{mN} / \mathrm{min}$. A second constant load hold period of $30 \mathrm{sec}$ at $10 \%$ of the maximum load was

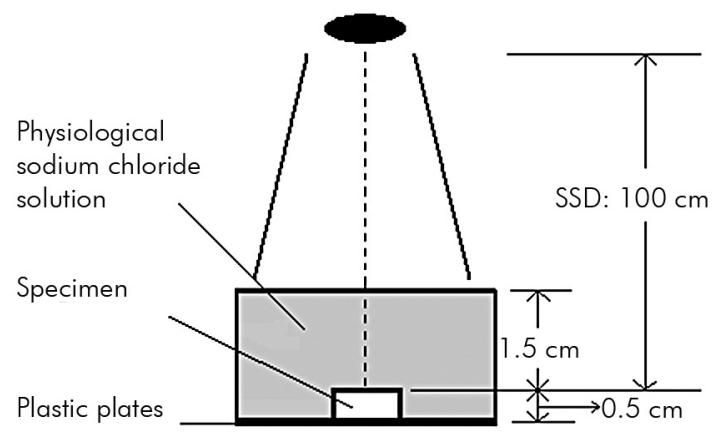

Figure 1. Radiation diagram. The black oval represents the radiation source (source-surface-distance, SSD): $100 \mathrm{~cm}$. During irradiation, the teeth were fixed on plastic plates (Technovit 4071VCL) and enclosed with physiological sodium chloride solution for homogeneous irradiation.

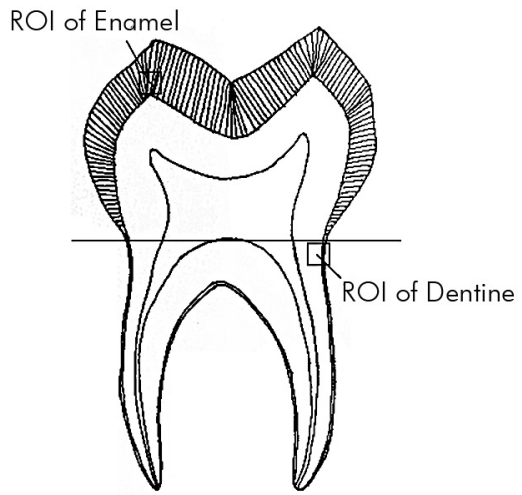

Figure 2. Indentation locations. In each half tooth, a $2 \times 2 \mathrm{~mm}^{2}$ region of interest (ROI) was marked in the enamel in the cusp zone and in the outer dentine near the enamel-dentine junction. Indents in every half tooth were performed in each $\mathrm{ROI}$ regardless of the dose. 
applied to correct the displacement data for thermal drift. Six indents were performed in every slab, and a $500 \mu \mathrm{m}$ gap at intervals of every two indents was used to prevent any mutual influence.

The effect of irradiation on human dental tissue can be characterized by the measurement of nano-mechanical properties using a well-known material science technique of nanoindentation or depth-sensing. This technique allows for the qualitative analysis of local nano-mechanical parameters, hardness and elastic modulus in small structures of inhomogeneous samples, which are inaccessible for conventional material testing. Therefore, the nanoindentation is predestined for measuring mechanical properties of dental tissue. This has been used effectively for the past 20 years. ${ }^{18}$

From the received load (F) and displacement (h), diagrams of the values of the nanohardness $(\mathrm{H})$ and the elastic modulus (E) were determined using the established method of Oliver and Pharr. ${ }^{23}$ The calculation of the hardness:

$\mathrm{H}=\mathrm{F} \_$max/A_c

The contact stiffness $S$ was calculated from the linear slope of the unload-displacement curve:

$$
\mathrm{S}=+\mathrm{dF} / \mathrm{dh}-_{-} \mathrm{I}_{-}\left(\mathrm{F}=\mathrm{F} \_ \text {max }\right)
$$

The scratch was loaded and unloaded using a constant loading rate; the constant load hold period was $40 \mathrm{sec}$. The tests were conducted to a maximum load of $2 \mathrm{mN}$, with a length of $13 \mu \mathrm{m}$ and intervals of two $10 \mu \mathrm{m}$ scratches. Thus, 50 teeth yielded 300 dentine and 300 enamel measurements of nanohardness and the elastic modulus as well as 100 measurements of the friction coefficient.

\section{Statistical analysis}

The nanohardness, elasticity and friction coefficients that were measured using the Triboindenter were analyzed. Subsequently, all data were calculated for each testing group. Then the test group data were compared with the control group data with one-way analysis of variance (ANOVA) followed by Dunnett's test. A one-way ANOVA followed by Tukey's test was used to compare the nano-mechanical properties of the 3 experimental groups. The percentage of change in $70 \mathrm{~Gy}$ radiation dose was compared to the control group for each specimen. Spearman's correlation analysis was conducted to analyze the effect of the radiation dose on the nano-mechanical properties. Results are presented as the mean and standard deviation. SAS 8.2 software (SAS Inc., Cary, USA) was used for analysis and a p-value of less than 0.05 was considered to be statistically significant.

\section{Results}

The elastic modulus, nanohardness and friction coefficient values in the enamel are shown in Table 1. The elastic modulus values showed significant differences for all experimental groups by one-way ANOVA compared to the non-irradiated controls: 10 Gy group, $p=0.042,30$ Gy group $p=0.027,50 \mathrm{~Gy}$ group, $p=0.003$, and 70 Gy group, $p=0.003$. The between experimental group comparison showed significant differences $(p<0.05)$ between doses except between the 50 Gy and 70 Gy groups ( $p>0.05$ ). For nanohardness values, the one-way ANOVA showed significant differences for all experimental groups compared to the non-irradiated controls: 10 Gy group, $p=0.004,30$ Gy group $p=0.004,50$ Gy group, $p=0.002$, and $70 \mathrm{~Gy}$ group, $\mathrm{p}=0.002$. The between experimental group comparison showed significant differences $(p<0.05)$ between doses except between the $10 \mathrm{~Gy}$ and 30 Gy groups $(p>0.05)$. While similar results were seen for the friction coefficient, the one-way ANOVA showed significant differences for allexperimental groups compared to the non-irradiated controls: $10 \mathrm{~Gy}$ group $\mathrm{p}=0.008,30$ Gy group $\mathrm{p}=0.040,50 \mathrm{~Gy}$ group $p=0.003$, and 70 Gy group $p=0.015$. The between experimental group comparison showed significant differences $(p<0.05)$ between doses except between the 10 Gy and 30 Gy groups ( $p>0.05$ ).

The elastic modulus, nanohardness and friction coefficient values in dentine are shown in Table 2. The elastic modulus values showed significant differences for all experimental groups by one-way ANOVA compared to the non-irradiated controls: 10 Gy group, $p=0.027,30$ Gy group $p=0.006,50$ Gy group, $p=0.002$, and 70 Gy group, $p=0.002$. The between experimental group comparison showed significant differences between all doses $(p<0.05)$. For nanohardness values, the one-way ANOVA showed significant differences for all experimental groups compared to the non-irradiated controls: 10 Gy group $p=0.033$, 
30 Gy group $p=0.037,50$ Gy group $p=0.003$, and 70 Gy group $p=0.002$. The between experimental group comparison showed significant differences between all doses $(p<0.001)$. In the friction coefficient values, the one-way ANOVA showed significant differences for all experimental groups compared to the non-irradiated controls: 10 Gy group $\mathrm{p}=0.007$, 30 Gy group $p=0.012,50$ Gy group, $p=0.024$, and 70 Gy group $p=0.026$. The between experimental group comparison showed significant differences between all doses $(p<0.05)$.

Thenanohardness was reduced by $87 \%$ and the elastic modulus by $78 \%$ in enamel, just as the nanohardness was reduced by approximately $73 \%$ and the elastic modulus by $75 \%$ in dentine (Figures 3 and 4). During the $5^{\text {th }}$ week after receiving $50 \mathrm{~Gy}$, nanohardness was reduced by approximately $60 \%$ and $31 \%$ for enamel and dentine, respectively (Figure 3), and the elastic modulus was reduced by approximately $36 \%$ and $44 \%$, respectively (Figure 4). The highest dose variation rate within the test groups fell in the range of 30-50 Gy. With the increasing radiation dose, the increase in the friction coefficient reached $287 \%$ in enamel and $44 \%$ in dentine (Figure 5). Thus, the increase in the friction coefficient in dentine was not as pronounced as in enamel. The maximum rate of change in the friction coefficient was increased by approximately $88 \%$ for enamel after irradiation at doses ranging from 30 to $50 \mathrm{~Gy}$ and was increased by $21 \%$ for dentine after irradiation at doses ranging from 0 to $10 \mathrm{~Gy}$ (Figure 5).

Analysis of correlations between the radiation dose and the mechanical properties of enamel showed that elastic modulus $(r=-0.61, p=0.014)$ and nanohardness $(r=-0.58, p=0.011)$ had a significant negative correlation with radiation dose, and friction coefficient had a significant positive correlation with radiation dose $(\mathrm{r}=0.84, \mathrm{p}=0.001)$. For dentine, the elastic modulus $(\mathrm{r}=-0.38, \mathrm{p}=0.019)$ and nanohardness $(\mathrm{r}=-0.32$, $\mathrm{p}=0.037)$ had a significant negative correlation with radiation dose, and the friction coefficient had a significant positive correlation with radiation dose $(\mathrm{r}=0.30, \mathrm{p}<0.001)$.

Table 1. Effects of radiation dose on enamel.

\begin{tabular}{|c|c|c|c|c|c|c|c|c|c|}
\hline $\begin{array}{l}\text { Dose } \\
\text { (Gy) }\end{array}$ & $\begin{array}{l}\text { Elastic modulus } \\
\qquad(\mathrm{GPa})\end{array}$ & $\begin{array}{c}\text { p-value } \\
\text { vs control } \\
\text { non-irradiated }\end{array}$ & $\begin{array}{l}\mathrm{p} \text {-value between } \\
\text { groups }\end{array}$ & $\begin{array}{c}\text { Nanohardness } \\
\text { (GPa) }\end{array}$ & $p$-value & $\begin{array}{c}\mathrm{p} \text {-value between } \\
\text { groups }\end{array}$ & $\begin{array}{l}\text { Friction } \\
\text { Coefficient }\end{array}$ & $\mathrm{p}$-value & $\begin{array}{l}\mathrm{p} \text {-value between } \\
\text { groups }\end{array}$ \\
\hline 0 & $97.35 \pm 15.92$ & - & - & $4.55 \pm 0.90$ & - & - & $0.23 \pm 0.02$ & - & - \\
\hline 10 & $73.82 \pm 5.96$ & $0.042^{*}$ & $\begin{array}{l}0.039^{*} \text { vs } 30 \mathrm{~Gy}, \\
0.002^{*} \text { vs } 50 \mathrm{~Gy}, \\
0.002^{*} \text { vs } 70 \mathrm{~Gy} .\end{array}$ & $2.19 \pm 0.40$ & $0.004^{*}$ & $\begin{array}{l}0.062 \text { vs } 30 \mathrm{~Gy} \\
0.0003^{*} \text { vs } 50 \mathrm{~Gy}, \\
0.0002^{*} \text { vs } 70 \mathrm{~Gy} .\end{array}$ & $0.35 \pm 0.05$ & $0.008^{*}$ & $\begin{array}{l}0.0548 \text { vs } 30 \mathrm{~Gy}, \\
0.0002^{*} \text { vs } 50 \mathrm{~Gy}, \\
0.0003^{*} \text { vs } 70 \mathrm{~Gy} .\end{array}$ \\
\hline 30 & $65.60 \pm 7.30$ & $0.027^{*}$ & $\begin{array}{l}0.0007^{*} \text { vs } 50 \mathrm{~Gy}, \\
0.0006^{*} \text { vs } 70 \mathrm{~Gy}\end{array}$ & $2.03 \pm 0.52$ & $0.004^{*}$ & $\begin{array}{l}0.0003^{*} \text { vs } 50 \mathrm{~Gy}, \\
0.0004^{*} \text { vs } 70 \mathrm{~Gy}\end{array}$ & $0.34 \pm 0.05$ & $0.040^{*}$ & $\begin{array}{l}0.0003^{*} \text { vs } 50 \mathrm{~Gy}, \\
0.0001^{*} \text { vs } 70 \mathrm{~Gy}\end{array}$ \\
\hline 50 & $31.88 \pm 7.11$ & $0.003^{*}$ & 0.0523 vs $70 \mathrm{~Gy}$ & $0.82 \pm 0.32$ & $0.002^{*}$ & $0.0008^{*}$ vs $70 \mathrm{~Gy}$ & $0.64 \pm 0.05$ & $0.003^{*}$ & $0.006^{*}$ vs $70 \mathrm{~Gy}$ \\
\hline 70 & $21.10 \pm 10.03$ & $0.003^{*}$ & & $0.57 \pm 0.20$ & $0.0021^{*}$ & & $0.89 \pm 0.1$ & 0.015 & \\
\hline
\end{tabular}

*Significant differences between the control and test groups.

Table 2. Effects of radiation dose on dentine.

\begin{tabular}{|c|c|c|c|c|c|c|c|c|c|}
\hline $\begin{array}{l}\text { Dose } \\
\text { (Gy) }\end{array}$ & $\begin{array}{l}\text { Elastic modulus } \\
\qquad(\mathrm{GPa})\end{array}$ & $p$-value & $\begin{array}{l}\mathrm{p} \text {-value between } \\
\text { groups }\end{array}$ & $\begin{array}{l}\text { Nanohardness } \\
\text { (GPa) }\end{array}$ & -value & $\begin{array}{l}\mathrm{p} \text {-value between } \\
\text { groups }\end{array}$ & $\begin{array}{l}\text { Friction } \\
\text { Coefficient }\end{array}$ & $p$-value & $\begin{array}{l}\mathrm{p} \text {-value between } \\
\text { groups }\end{array}$ \\
\hline 0 & $29.26 \pm 4.23$ & - & - & $0.78 \pm 0.10$ & . & - & $0.39 \pm 0.03$ & & - \\
\hline 10 & $18.14 \pm 2.45$ & 0.027 & $\begin{array}{l}0.041^{*} \text { vs } 30 \mathrm{~Gy}, \\
0.0001 \text { * vs } 50 \mathrm{~Gy}, \\
0.0001 \text { * vs } 70 \mathrm{~Gy}\end{array}$ & $0.54 \pm 0.06$ & $0.033^{*}$ & $\begin{array}{l}0.0006^{*} \text { vs } 30 \mathrm{~Gy} \\
<0.001^{*} \text { vs } 50 \mathrm{~Gy} \\
0.0002^{*} \text { vs } 70 \mathrm{~Gy}\end{array}$ & $0.47 \pm 0.01$ & $0.007^{*}$ & $\begin{array}{l}0.044^{*} \text { vs } 30 \mathrm{~Gy}, \\
0.032^{*} \text { vs } 50 \mathrm{~Gy}, \\
0.029^{*} \text { vs } 70 \mathrm{~Gy} .\end{array}$ \\
\hline 30 & $13.17 \pm 1.34$ & & $\begin{array}{l}0.0003^{*} \text { vs } 50 \mathrm{~Gy}, \\
0.0003^{*} \text { vs } 70 \mathrm{~Gy}\end{array}$ & $0.41 \pm 0.05$ & & $\begin{array}{l}0.0003^{*} \text { vs } 50 \mathrm{~Gy}, \\
0.0003^{*} \text { vs } 70 \mathrm{~Gy}\end{array}$ & $0.49 \pm 0.01$ & & $\begin{array}{l}0.031^{*} \text { vs } 50 \mathrm{~Gy}, \\
0.0006^{*} \text { vs } 70 \mathrm{~Gy}\end{array}$ \\
\hline 50 & $7.41 \pm 1.80$ & $0.002^{*}$ & $0.037^{*}$ vs $70 \mathrm{~Gy}$ & $0.28 \pm 0.11$ & $0.003^{*}$ & $0.0006^{*}$ vs $70 \mathrm{~Gy}$ & $0.52 \pm 0.01$ & $0.024^{*}$ & $0.020 *$ vs $70 \mathrm{~Gy}$ \\
\hline 70 & $7.27 \pm 1.01$ & $0.002^{*}$ & & $0.41 \pm 0.05$ & $0.002^{*}$ & & $0.56 \pm 0.05$ & $0.026^{*}$ & \\
\hline
\end{tabular}

*Significant differences between the control and test groups. 


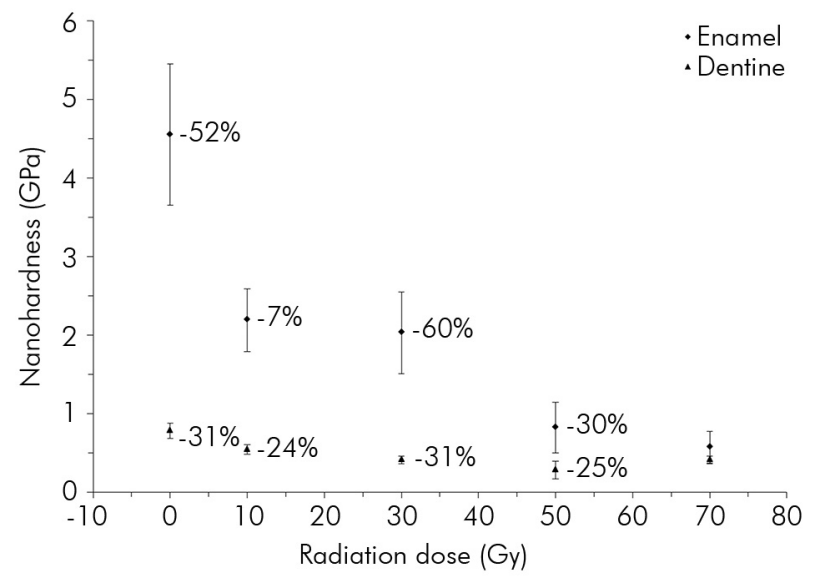

Figure 3. Change in the nanohardness of enamel and dentine. The number underlined on the graph shows the largest \% change in value between the test groups.

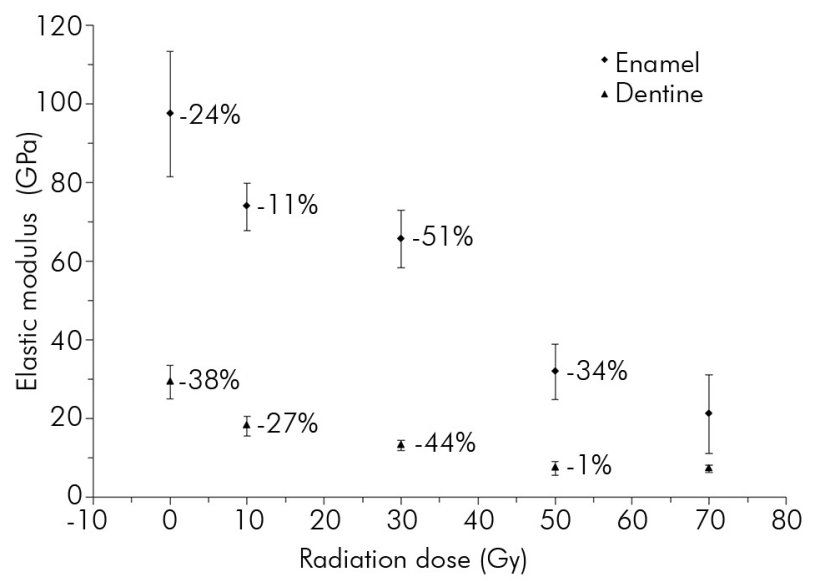

Figure 4. Change in the elastic modulus of enamel and dentine. The number underlined on the graph shows the largest $\%$ change in value between the test groups.

\section{Discussion}

The aim of this investigation was to test the hypothesis that high energy X-ray irradiation at different doses adversely affects the nano-mechanical properties (elastic modulus, nanohardness and friction coefficient) of dental hard tissue. The results show that exposure to $\mathrm{X}$-rays caused significant damage in terms of nano-mechanical properties. The damage to both enamel and dentine was also dose related, and there was a significant correlation with dose and the nano-mechanical properties of both enamel and dentine. The teeth showed decreased fracture resistance, and they were more fragile. This may

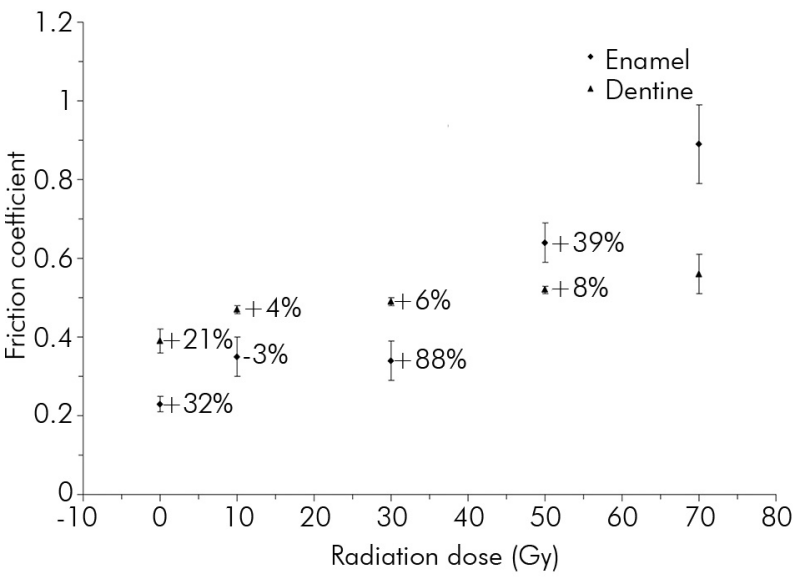

Figure 5. Change in the friction coefficient of enamel and dentine. Data expressed with radiation dose and $95 \%$ confidence intervals. The number underlined on the graph shows the largest \% change in value between the test groups.

increase the susceptibility to caries or lead to the rapid development of caries.

In dental literature, studies dealing with the effects of radiotherapy on dental hard tissues have mainly focused on enamel. . $^{1,17,24,25,26,27}$ However, only limited information is available concerning these effects on both enamel and dentine. Moreover, most of the previous investigations had limitations with regard to the instruments used, and there has been little study concerning the relationship between radiation dose and mechanical properties. Compared with previous studies using Keitz's nanohardness tester, ${ }^{16}$ the Triboindenter provides high contrast, high-resolution images and involves the use of non-invasive test methods. The current in vitro study on enamel and dentine demonstrated radiation-induced changes in their mechanical properties (elastic modulus, nanohardness and friction coefficient). The relatively high variance of values obtained regarding the nano-mechanical properties are explained by the use of individual teeth, which were subjected to different environmental factors during the time of tooth formation and individual mineralization.

The influence of the storage solution has been of concern in some studies because it may influence the nano-mechanical properties of the samples, but we hope that in this study, we have introduced measures to prevent any damage to the enamel or 
dentine because all of the enamel and dentine slabs were stored in daily-renewed solution that had been previously demonstrated to be suitable ${ }^{20,21}$ at the same temperature and humidity for identical time periods. The physiological sodium chloride solution we used has also been verified to cause minimum damage to teeth during an irradiation study. ${ }^{22}$ We also used a control that was not treated with radiation. With respect to the variance of the values obtained in our study, it appears that there were only marginal changes in the nanohardness, elastic modulus and friction coefficient of samples that were stored. Therefore, it may be concluded that the significant variations in the results solely depended on the different radiation doses that were used.

The mechanical changes caused by irradiation can be explained by the decarboxylation of the tissue. The organic matrix interacts with the apatite crystals via calcium ions from electrostatic binding of collagen side chains, carboxylate and surface mineral phosphate groups. Decarboxylation demands a supply of sufficient high energy. The ability to overcome the binding energy seems to increase with high X-ray energy. Because collagen consists of macromolecular chains of various types of amino acids, irradiation can promote side chain decarboxylation and a loss of acidic phosphate groups with the formation of new calcium ion bridged phosphate groups. Consequently, a mineral-organic interaction might occur between apatite and collagen and thus may induce micro cracks in the hydroxyapatite mineral; ${ }^{28}$ its supercoiled triple helix conformation is sensitive to different levels of radiation. ${ }^{29}$

The results of the present study indicated that after exposure to a range of radiation doses, the nanohardness and elastic modulus was significantly decreased; they were negatively correlated with X-ray dose and differed significantly when compared with the non-exposed control group ( $\mathrm{p}<0.05)$. The friction coefficient was found to be positively correlated with the X-ray dose and was significantly higher than in the non-exposed control group ( $<<0.05)$. For the radiation doses that were used in the current investigation, the structure of enamel and dentine might be affected differently by irradiation; there was a dramatic effect on the nano-mechanical properties of enamel. A possible explanation as to why radiation treatment had a greater effect on the nano-mechanical properties of enamel than on those of dentine is that enamel contains considerably less organic material. The collagen contained in dentine is reinforced by intrafibrillar mineral deposits, while each fibril is surrounded by extrafibrillar mineral deposits. ${ }^{28}$ The intrafibrillar minerals that stiffen the collagen fibrils dominate the elastic behavior of dentine under normal loading conditions. High energy X-ray irradiation may destroy the intrafibrillar minerals, and this destruction may become more severe with increasing radiation dose.

In our study, the test groups were exposed to radiation once a day at a dose of $2 \mathrm{~Gy} /$ fraction administered 5 days/week, which was similar to the standard protocol that was used for the clinical treatment of head and neck cancer. Usually, therapeutic irradiation starts at a dose of 2 Gy on the first day of treatment and reaches $50 \mathrm{~Gy}$ at the end of the $5^{\text {th }}$ week of treatment. Our results suggested that after exposure to X-rays for 5 weeks, the fracture resistance of the teeth had obviously decreased, and they were prone to be more fragile. The mechanical changes in dental hard tissue might increase susceptibility to the development of caries or lead to the rapid development of caries. Total doses in excess of 50 Gy had little additional effect. Radiation doses of $30-50 \mathrm{~Gy}$, which corresponded with the $15^{\text {th }}-25^{\text {th }}$ day of radiotherapy (excluding weekends), could be the key doses and time points over which measures for preventing radiation caries should be applied.

This study has some limitations. Any investigation that relies on isolated teeth cannot completely mimic the clinical situation, thus these results, despite being performed under strict conditions, may not fully reveal the nature of patients' teeth after undergoing radiotherapy. We also selected only three parameters to test the mechanical strength of the teeth. Other factors have also been demonstrated to be important to the mechanical strength of enamel and dentine and so may eventually impact the likelihood of a patient developing radiation caries. These include ultimate tensile strength ${ }^{6,7}$ fracture resistance, ${ }^{8}$ and microleakage ${ }^{30}$ as well as bonding of resin-based composites to enamel and dentine. ${ }^{9}$ 


\section{Conclusion}

Radiotherapy caused nano-mechanical changes in dentine and enamel that were dose related. The key doses were 30-50 Gy and the key time points were the $15^{\text {th }}-25^{\text {th }}$ days of treatment. These results suggest that for the radiation caries problem, doctors should be aware of their patient's stage of radiotherapy and offer them very specific, targeted advice to protect their teeth. In addition, the changes in dental morphology and crystal phase transfer on a micro-scale, as well as the design of radiotherapy protocols and the limitation of radiation dose for head and neck cancer patients, require evaluation in further studies.

\section{References}

1. Argiris A, Karamouzis MV, Raben D, Ferris RL. Head and neck cancer. Lancet. 2008;371(9625):1695-709. doi:10.1016/S0140-6736(08)60728-X

2. Burlage FR, Coppes RP, Meertens H, Stokman MA, Vissink A. Parotid and submandibular/sublingual salivary flow during high dose radiotherapy. Radiother Oncol. 2001;61(3):271-4. doi:10.1016/S0167-8140(01)00427-3

3. Denham JW, Peters LJ, Johansen J, Poulsen M, Lamb DS, Hindley A et al. Do acute mucosal reactions lead to consequential late reactions in patients with head and neck cancer? Radiother Oncol. 1999;52(2):157-64. doi:10.1016/S0167-8140(99)00107-3

4. Vissink A, Jansma J, Spijkervet FK, Burlage FR, Coppes RP. Oral sequelae of head and neck radiotherapy. Crit Rev Oral Biol Med. 2003;14(3):199-212. doi:10.1177/154411130301400305

5. Kielbassa AM, Hinkelbein W, Hellwig E, Meyer-Luckel H. Radiation-related damage to dentition. Lancet Oncol. 2006;7(4):326-35. doi:10.1016/S1470-2045(06)70658-1

6. Soares CJ, Castro CG, Neiva NA, Soares PV, Santos-Filho PC, Naves LZ et al. Effect of gamma irradiation on ultimate tensile strength of enamel and dentin. J Dent Res. 2010;89(2):159-64. doi:10.1177/0022034509351251

7. Soares CJ, Neiva NA, Soares PB, Dechichi P, Novais VR, Naves LZ et al. Effects of chlorhexidine and fluoride on irradiated enamel and dentin. J Dent Res. 2011;90(5):659-64. doi:10.1177/0022034511398272

8. Soares CJ, Roscoe MG, Castro CG, Santana FR, Raposo LH, Quagliatto PS et al. Effect of gamma irradiation and restorative material on the biomechanical behaviour of root filled premolars. Int Endod J. 2011;44(11):1047-54. doi:10.1111/j.1365-2591.2011.01920.x

9. Naves LZ, Novais VR, Armstrong SR, Correr-Sobrinho L, Soares CJ. Effect of gamma radiation on bonding to human

\section{Acknowledgements}

This study was undertaken with funding provided by the Special Fund for Health Research in the Public interest (No. 201002017).

Weareindebted to Professor Baisen(Chief Technician, Cancer Center of WestChina Hospital, Sichuan University, Chengdu, China) for his guidance regarding the irradiation of the enamel and dentine samples.

Li Ji-Yao conceived and designed the experiments. Liang Xue performed the experiments. Liang Xue and Zhang Jing-Yang analyzed the data. Liang Xue, Zhang Jing-Yang and Cheng Iek Ka contributed reagents/materials/analysis tools.

enamel and dentin. Support Care Cancer. 2012;20(11):2873-8. doi:10.1007/s00520-012-1414-y

10. Dreizen S, Daly TE, Drane JB, Brown LR. Oral complications of cancer radiotherapy. Postgrad Med. 1977;61(2):85-92.

11. Frank RM, Herdly J, Philippe E. Acquired dental defects and salivary gland lesions after irradiation for carcinoma. J Am Dent Assoc. 1965;70(8)68-83. doi:10.14219/jada.archive.1965.0220

12. Nagler RM. The enigmatic mechanism of irradiation-induced damage to the major salivary glands. Oral Dis. 2002;8(3):141-6. doi:10.1034/j.1601-0825.2002.02838.x

13. Schwarz E, Chiu GK, Leung WK. Oral health status of southern Chinese following head and neck irradiation therapy for nasopharyngeal carcinoma. J Dent. 1999;27(1):21-8. doi:10.1016/S0300-5712(98)00024-4

14. Franzel W, Gerlach R. The irradiation action on human dental tissue by X-rays and electrons--a nanoindenter study. Z Med Phys. 2009;19(1):5-10. doi:10.1016/j.zemedi.2008.10.009

15. Grötz KA, Duschner H, Kutzner J, Thelen M, Wagner W. [New evidence for the etiology of so-called radiation caries. Proof for directed radiogenic damage od the enamel-dentin junction]. Strahlenther Onkol. 1997;173(12):668-76. German. doi:10.1007/BF03038449

16. Kielbassa AM, Beetz I, Schendera A, Hellwig E. Irradiation effects on microhardness of fluoridated and non-fluoridated bovine dentin. Eur J Oral Sci. 1997;105(5 Pt 1):444-7. doi:10.1111/j.1600-0722.1997.tb02142.x

17. Kielbassa AM, Hellwig E, Meyer-Lueckel H. Effects of irradiation on in situ remineralization of human and bovine enamel demineralized in vitro. Caries Res. 2006;40(2):130-5. doi:10.1159/000091059

18. Angker L, Swain M. Nanoindentation: application to dental hard tissue investigations. Journal of materials research. 2006;21(08):1893-905. doi:10.1557/jmr.2006.0257 
19. He LH, Swain MV. Enamel - a "metallic-like" deformable biocomposite. J Dent. 2007;35(5):431-7. doi:10.1016/j.jdent.2006.12.002

20. Fränzel W, Gerlach R, Hein HJ, Schaller HG. Effect of tumor therapeutic irradiation on the mechanical properties of teeth tissue. Z Med Phys. 2006;16(2):148-54. doi:10.1078/0939-3889-00307

21. Hall AF, Buchanan CA, Millett DT, Creanor SL, Strang R, Foye RH. The effect of saliva on enamel and dentine erosion. J Dent. 1999;27(5):333-9. doi:10.1016/S0300-5712(98)00067-0

22. Eckardt I, Henning S, Syrowatka F, Gerlach R, Hein HJ. [Mechanical changes in bone after roentgen irradiation with low dosage]. Radiologe. 2001;41(8):695-9. German. doi:10.1007/s001170170120

23. Oliver WC, Pharr GM. An improved technique for determining hardness and elastic modulus using load and displacement sensing indentation experiments. Journal of materials research. 1992;7(06):1564-83. doi:10.1557/JMR.1992.1564

24. Aoba T, Takahashi J, Yagi T, Doi Y, Okazaki M, Moriwaki Y. High-voltage electron microscopy of radiation damages in octacalcium phosphate. J Dent Res. 1981;60(5):954-9. doi:10.1177/00220345810600051801
25. Geoffroy M, Tochon-Danguy HJ. Long-lived radicals in irradiated apatites of biological interest: an e.s.r. study of apatite samples treated with 13CO2. Int J Radiat Biol Relat Stud Phys Chem Med. 1985;48(4):621-33. doi:10.1080/09553008514551681

26. Kielbassa AM, Schendera A, Schulte-Monting J. Microradiographic and microscopic studies on in situ induced initial caries in irradiated and nonirradiated dental enamel. Caries Res. 2000;34(1):41-7. doi:10.1159/000016568

27. Shulin W. Human enamel structure studied by high resolution electron microscopy. Electron Microsc Rev. 1989;2(1):1-16. doi:10.1016/0892-0354(89)90008-7

28. Hübner W, Blume A, Pushnjakova R, Dekhtyar Y, Hein HJ. The influence of $X$-ray radiation on the mineral/organic matrix interaction of bone tissue: an FT-IR microscopic investigation. Int J Artif Organs. 2005;28(1):66-73.

29. Moscovich H, Creugers NH, Jansen JA, Wolke JG. In vitro dentine hardness following gamma-irradiation and freezing. J Dent. 1999;27(7):503-7. doi:10.1016/S0300-5712(99)00005-6

30. Bulucu B, Avsar A, Demiryürek EO, Yesilyurt C. Effect of radiotherapy on the microleakage of adhesive systems. J Adhes Dent. 2009;11(4):305-9. 